\title{
Citizens or Consumers? Air Quality Sensor Users and Their Involvement in Sensor.Community. Results from Qualitative Case Study
}

\author{
Michał Wróblewski *, Joanna Suchomska (D) and Katarzyna Tamborska
}

Department of Philosophy and Social Sciences, Faculty of Sociology, Nicolaus Copernicus University in Torun, 87-100 Toruń, Poland; joanna.suchomska@gmail.com (J.S.); katarzyna.tamborska@umk.pl (K.T.)

* Correspondence: michwrob@umk.pl

Citation: Wróblewski, M.

Suchomska, J.; Tamborska, K.

Citizens or Consumers? Air Quality Sensor Users and Their Involvement in Sensor.Community. Results from Qualitative Case Study. Sustainability 2021, 13, 11406. https://doi.org/ $10.3390 /$ su132011406

Academic Editor: Elena Cristina Rada

Received: 31 August 2021

Accepted: 12 October 2021

Published: 15 October 2021

Publisher's Note: MDPI stays neutral with regard to jurisdictional claims in published maps and institutional affiliations.

Copyright: (c) 2021 by the authors. Licensee MDPI, Basel, Switzerland. This article is an open access article distributed under the terms and conditions of the Creative Commons Attribution (CC BY) license (https:// creativecommons.org/licenses/by/ $4.0 /)$.

\begin{abstract}
This article presents the results of the qualitative research conducted on Polish users of the Sensor.Community network. Different types of motivation behind the decision to engage in the collection of air quality data are discussed. Users' motives have been found to result predominantly from the concern for the health and safety of their loved ones, as well as the need to control air quality (and ultimately the quality of life) in their immediate environment (home and neighbourhood). Users do not display civic behaviour such as working for the local community. Three factors have been proposed to explain this status quo. First, the motives related to health and safety, as opposed to motives behind seeking a resolution to an environmental problem at the local level, may contribute to the solidification of individualistic attitudes. Second, Sensor.Community is organised in a way that does not promote a greater involvement from the network organisers in the development of the initiative and retention of users. Instead, the network focuses predominantly on the technical aspects of operation. Third, users have no sense of agency as, in our opinion, they remain largely unaware of the value of the data they collect.
\end{abstract}

Keywords: citizen science; air pollution; citizen engagement; monitoring; environmental data

\section{Introduction}

Pollution levels in Poland are among the highest in the entire European Union (EU) [1]. Particulate matter PM10 and PM2.5 pose a significant challenge along with carcinogenic benzo[a]pyrene (B[a]P). For several years, air quality has constituted a vital element of Polish public debate which gains in intensity every heating season in winter. According to nationwide public opinion polls [2], nearly half of the country's inhabitants consider smog (Smog is an expression used both in scientific discourse and in everyday speech. Strictly speaking, the term originally referred to air pollution problems that occurred in the UK in the 20th century [3]. It is now a term used to describe a combination of different pollutants. In this article, smog is mainly understood as pollution related to particular matters (PM) defined as "air pollutant consisting of a mixture of solid and liquid particles suspended in the air" [4] (p. 3) to be a serious problem in their place of residence. Parallelly, a dynamic movement of urban activists which focused on this issue has developed, striving to improve the situation by lobbying for legislative acts that can contribute to environmental protection $[5,6]$. This movement comprises a community of committed people who most frequently operate by means of local initiatives known in Poland as 'smog alerts' (in Polish: alarmy smogowe). The interest in smog seems to also be related to the growing popularity and utility of data in social life, combined with the access to mobile technologies employed in monitoring various forms of daily activity [7].

All over the world, air quality has become a topic widely studied as part of citizen science. Citizens are using low-cost and readily available sensors and mobile applications to collect data on pollutants at their places of daily operation. This interest in generating 
non-expert, bottom-up knowledge on air quality is rising in Poland as well. The largest initiative of this type in Poland is Sensor.Community (previously known as Luftdaten.info). It started to operate locally in Stuttgart [8], one of Germany's largest cities, and now operates in 71 countries with over 14,000 sensors (https: / / sensor.community/pl/, accessed on 9 August 2021).

This article presents the results of a research analysis conducted on a group of people who contribute to the Sensor.Community network. An air quality sensor is a device with specific technical parameters that can be evaluated in terms of reliability or efficiency. However, citizen measurement is also a social practice, driven by specific motives and associated with specific meanings and senses. The main objective of the study was to understand the social aspects of air quality sensor use. In the study, we focused on:

- $\quad$ motivations - what made users decide to monitor air quality? what social values accompany involvement in the Sensor.Community initiative?

- $\quad$ modes of use in the social sphere-in which social activities did users use the data?

- $\quad$ potential for activation - to what extent did sensor use lead to changing attitudes and getting involved in the advocacy activism for better air quality?

- $\quad$ involvement in the development of Sensor.Community-to what extent does the use of a low-cost sensor contribute to the development of the entire network? What ideas do users have for the development of the initiative?

The analysis begins-first-with a review of the research on citizen science projects dedicated to air quality. Second, the history of the Sensor.Community initiative is presented along with its mode of operation and inclusion procedures for new users, after which the research methodology and key findings are described. Finally, the vital factors for user involvement in collecting air pollution data within this initiative are discussed.

\section{Citizen Science and Air Quality: The Conceptual Framework and Current State of Research}

Citizen science is a collection of research practices employed by laypeople to generate knowledge in non-institutional communities (i.e., communities not associated with academic science) which are recognised by experts. The concept is used to analyse civic research practices $[9,10]$ and citizen involvement in generating knowledge about environmental protection [11,12] and public health [13]. The basic premise behind citizen science and its contribution to scientific knowledge is the belief that local knowledge, embedded in a specific social context and closely related to specific living conditions, may constitute a necessary supplement to expert knowledge [14]. The latter is said to carry certain limitations due to the hierarchisation of issues explored by science, whereby certain research areas addressed by scientists may not necessarily be the most desired ones in terms of social interest [15], areas of research left unfunded and incomplete (undone science), as well as gaps in expert knowledge that can be successfully filled by non-experts $[16,17]$.

Given its nature (possible direct health risks) and the development of measurement technology, air quality has promptly become the focus of numerous citizen science projects and actions. First initiatives involving the use of private sensors date back to the 1970s [18]. Public participation in the collection of data on air pollution is frequently politically motivated as part of local communities' ongoing pursuit of a better quality of life. It may also be driven by the ignorance of authorities towards environmental issues recognised as health risks by citizens [19], criticism of local authorities regarding incomplete data (the problem of 'white spots'), or data interpretation [20]. Environmental justice is spreading as a perspective [21], with easily accessible technology (e.g., low-cost sensors) serving as an important tool in the legitimisation of political claims and compensation for negative health effects [22]. Some citizen science projects are organised by the public sector (local authorities, environment monitoring institutions) to encourage the participation of citizens. Such a model is based on cooperation rather than antagonism, whereby the citizen-science approach is intended as a means of local participation rather than political mobilisation. Examples of such initiatives include the CurieuzeNeuzen Vlaanderen project in Belgium [8,23] and the AirBox project in Taiwan [24]. 
While this article focuses on citizen science in terms of air quality, it is worth noting that civic monitoring applies to other areas as well and includes studies of noise pollution (e.g., Noise Tube Project; [25]), river pollution [26], and water monitoring in shale gas extraction areas [27].

There are many positive aspects of citizen science, along with air quality monitoring. The most obvious one is the educational value of spreading knowledge about environmental risks [28]. Projects of this type may also contribute to improved levels of trust in public institutions [8], better relations between citizens and institutions [29], further development of activist and civic attitudes, and the legitimisation of the citizens' perspective in the eyes of professionals [12,30]. Many citizen science projects are found to be of particular value in urban contexts [26,31]. Data collected by citizens are taken into consideration by city planners and employed in air quality health impact analyses in specific districts [18]. Citizen science initiatives can also support sustainable development by identifying key problems and challenges in addition to mobilising large resources to generate the relevant knowledge [32].

However, researchers identified certain problems related to citizen science. Typically, projects of this type involve privileged groups, for example, from the middle classes [33]. Another issue is when the technological aspect of the project takes over the social one, which poses a risk of reduced citizen participation [27].

\section{Case Study Description and Methodology}

This article presents the results of our qualitative case study research on users of low-cost air quality sensors operating as part of the Sensor.Community social project (previously known as Luftdaten). Groups of local activists who have been meeting regularly in the laboratories as part of the Code for Germany programme of the Open Knowledge Foundation Germany formed OK Lab Stuttgart, whose work resulted in the Luftdaten.info project. The idea was to use low-cost sensors to provide the open data on PM10 and PM2.5 air pollution as an expression of a civic response to a lack of official information. A similar problem had been identified by Warsaw activists working to improve air quality, who wanted to also implement the practice of citizen monitoring in Poland. Technically, the project is based on the self-assembly and installation of the measuring devices on the outside walls of houses.

The initiative in its current scope of Sensor.Community makes it possible to obtain data from different regions worldwide. It is particularly valuable in areas excluded from official monitoring, with poor (large cities) or non-existent (rural areas) coverage by public networks. The majority of these sensors are located in Europe; however, they are present on all continents (except Antarctica), e.g., in the United States and Russia. Currently, in Poland there are about 800 such sensors, most of which are located in Warsaw and other large cities (Wroclaw, Krakow, Gdansk, Lodz).

The sensor kit (Node MCU SDS011) is made of universal components like an electronic module for WiFi communication, fine dust sensor, temperature, humidity and pressure sensor, cables, and plastic hydraulic elbows for weather protection. That allows building a relatively light, small (about $20 \mathrm{~cm}$ long) and cheap device (for about 50 euro). The raw data from particular sensors can then be transferred to an online map which makes it possible to check the value readings of particular matters measured in micrograms per cubic meter over the last $24 \mathrm{~h}$ in different locations. Information on temperature, humidity, and pressure (those parameters are important for the sensor's operation) are also given. Graphically, the results are represented by hexagons with values varied by colour, from green to purple [8]. In addition to a wide observation area and the possibility of data aggregation, working within a network has other advantages like the ability to share and compare rates but requires meeting some challenges of connectivity. That imposes prerequisites of sensors equipped with electronic components which also requires some technical skills from users. The do-it-yourself character of the device also requires self-reliance in assembly (the user must think of the method of fixing it to the wall by her or himself). 
A grassroots community that focuses on providing logistic and technical support to organise individual citizen-based air quality monitoring stations, it offers instructions on how and where to buy the devices necessary to prepare and install sensors, while ensuring access to dedicated software. Part of the community's activity in Poland is to hold free open-access workshops for people who want to build their own sensors. There is also an international forum with information on new activities related to the operation of the network and technical support regarding the use of the sensor. This gives users access to information on possible solutions for technical problems.

The interactive map is one of the most important elements of the community's website (https:/ / sensor.community/en/, accessed on 9 August 2021), which displays the location of measurement points and contact details for local organisations promoting the initiative. Those interested can also learn the location and time of meetings within the network.

The Sensor.Community in Poland is animated and promoted primarily by the Warszawski Alarm Smogowy (Warsaw Smog Alert) association and Koduj dla Polski (Code for Poland) community. The first event to launch the network's operation in the country was a meeting held in 2018 in Warsaw with Lukas Mocek, a member of OK Lab, who shared his experiences from Stuttgart.

Our study of Sensor.Community's users in Poland was carried out in November and December, 2020. During the study conduction, the largest number of sensors (over 100) were located in Warsaw. In the other major cities, there were from a dozen to several dozen sensors. We applied a qualitative research method by conducting the study using qualitative interviews. The interview scenario was divided into several main thematic plots. The first one concerned the perception of the smog problem and existing data on air pollution, the monitoring system or the work of the monitoring actors. The second concerned the respondents' involvement in the Sensor.Community initiative, their motivations for being in the network and using an air quality sensor. We then interviewed the respondents about their experiences of working with sensor data, how they use it and how this translates into their daily activities. The last issue discussed was the perception of the role of the Sensor.Community initiative in stimulating public debate and action to protect air quality in Poland.

The group of respondents included people involved in the community's activities to varied degrees. A total of 21 semi-structured individual interviews were conducted based on a previously prepared scenario. The vast majority of the respondents were users of air quality sensors, out of which four played the role of network leaders in Poland: they organise air quality sensor assembly workshops for interested citizens, improve the technology and data visualisation, and join the initiatives of the Code for Poland community that implements IT projects for social welfare. The study group consisted of 20 men and one woman. They were of working age and professionally active (only one person was retired). The youngest respondent was 24 years old and the oldest was 62 years old. Most of the participants were between 30 and 45 years old. All of them lived in urban or suburban areas. Most of the respondents lived in the biggest city in Poland-Warsaw. Other people lived in such cities as: Poznan, Torun, Solec Kujawski. Nearly all of them dealt with new technologies professionally.

When recruiting the respondents, we cooperated with the leaders of local smog alerts (grassroots initiatives for air quality improvement) operating in Warsaw and the Kujawsko-Pomorskie Voivodeship, as well as with one of the leaders of Code for Poland. Consequently, the contact details (e-mail addresses) of people potentially interested in participating in the study were obtained. Those who replied positively to our invitation were enrolled in the study.

The interviews were conducted by 3 moderators-the authors of the article-via online communication platforms (Zoom or MS Teams), which allowed us to record the interviews. The interviews took between 45 and $90 \mathrm{~min}$. Due to the sanitary restrictions related to the ongoing SARS-CoV-2/COVID-19 pandemic, the meetings had to be held remotely. The collected material was transcribed and then encoded by interviewers by 
means of MAXQDA, a software package for qualitative data analysis. The codes used in the analysis were developed based on our research questions and subject literature which focused primarily on the respondents' motives behind the use of air quality sensors, their perception of their role in Sensor.Community, and the potential of user involvement and network operation in terms of civic participation.

It needs to be emphasised that from the start our study had not only scientific but also practical objectives. Its results were intended to provide the local network leaders in Poland with information on how to develop the initiative in terms of cooperation with users and the technological operation of the network.

\section{Description of the Results}

Most users were involved in the network for health and family reasons. This motivation also translated into how the sensor was used on a daily basis. The readings were often checked ad hoc before certain activities such as outdoor sports and going for a walk, particularly with children. The use of air quality sensors was also directly related to health problems (one of the respondents suffered from asthma) or poor conditions ('I became interested when I started to feel worse in winter' (I_15)).

Our respondents' interest in the environment and its impact on health can be associated with their discovery of the negative effects a given space can have on people's living conditions. This realisation came particularly with their travels or the need to move which drew their attention to the problem of poor air quality. Additionally, the sensor is intended to monitor its immediate surroundings, for example, the quality of fuel used by neighbours for heating. Ecological awareness is also connected with family life, or more precisely, users' desire to protect their loved ones:

'On top of that I have two children who are four and seven years old. Four years ago, our children were small. With my wife, we had this rule that we'd take them out every day to catch some fresh air, first in a pram and later for a walk. Once the alerts stated that the air was really bad on that day or we ourselves could see it or smell it, we began to wonder if we shouldn't take it into account when planning our walks' (I_11).

'When I came back to Warsaw and got off the plane, I thought I would suffocate compared to the air I was breathing before. I realised I could do something about it, something could be done. I know they have different geographical conditions, but that's just one thing. They put a lot of emphasis on air quality. I thought this could be done here' (I_20).

Moreover, most respondents believed that the data they collected could prove valuable to other people, for example, their neighbours, for health and family reasons as well: 'This is probably why we collect this data and send it to people so that they can take decisions that will potentially affect their health. There are days when the air is horrible, and they won't take children [for a walk]' (I_05).

The respondents' motives behind the collection of air quality data clearly correspond to the category of 'the sense of safety' (individually defined and related primarily to one's health and need to protect loved ones). The sensor serves as a tool that ensures protection against harmful exposure and enables the identification of risk-free spaces. This is visible in one of the most common ways of using the sensor-to verify the indoor air quality and compare it with the outdoor readings. As one of the respondents said, placing the sensor at home 'had its good side because we were able to confirm that it was indeed safer to stay at home and that it actually made a difference' (I_10). Therefore, the sensor seems to be used by the respondents as a tool to safeguard those close to them: 'I check if I and my closest family are safe at the moment when we are outside' (I_04).

When using the sensor, individual sensory experiences (visual and olfactory) are an important component. The collected data become a factor that supports one's direct experience: '(...) people (...) forget that this is an issue. Only when they start to feel poorly, they begin to wonder why' (I_20). At the same time, users are aware of the technological limitations of low-cost sensors. The latter do not meet the standards of public air quality 
monitoring networks and may, therefore, distort reality. However, a direct interaction with the sensor alters this opinion. By testing the sensor on their own, users no longer perceive it as a black box and see the collected data as more reliable. Consequently, a direct interaction with the sensor becomes an important source of its legitimacy:

'Without the sensor, I can rely on the available data, but having it physically [at home] I am more willing to believe this data. When I change its location, cover it or blow at it, I can see how the reading changes, how it reacts. This seems more credible to me' (I_15).

Technological limitations are also connected with the respondents' negative experiences of intervention attempts to improve air quality. The reliability of the data obtained with low-cost sensors can be easily questioned along with the legitimacy of claims made on their basis:

'City authorities ignore us and at meetings, go as far as to say that some sensors, including ours, produce false data because they are cheap. These people prefer to stick to some state regulations on smog measurement standards' (I_13).

Do you think this data can be used by the Chief Inspectorate of Environmental Protection?

'I doubt it because they have no supervision over where these sensors are installed and if they were installed correctly. Each sensor can be slightly different. Scientists need a reliable source that they can control. It is probably not a good source for them' (I_20).

This view is shared by some respondents who are themselves cautious about data quality:

'As usual, the problem lies in the quality of the data. Is this data reliable? You can measure anything with such a high degree of uncertainty or measurement inconclusiveness that it does nothing but encourage confusion. (...) Data quality is a major concern. For people who don't even use it, but only check it or contribute by whatever means they can. It depends how they themselves understand what they measure' (I_14).

Furthermore, the problem of data reliability may be related not only to the properties of measuring devices. While their technological limitations can be studied and recognised, the operating conditions of a civic-based network, users' attitudes and competences are much more difficult to control than those developed as part of the official employment relationship:

'You're not even obliged to upload high-quality data. Someone can deliberately distort the data just for fun. Why not? I can imagine that some people will do that. It is just as possible that someone - in good faith - will do things wrong and upload data in an unprofessional or incorrect way' (I_14).

A characteristic feature of the sensor is its convenience. Users are primarily concerned with comfort, seeking to make the sensor as comfortable and efficient as possible. An important advantage of Sensor.Community - according to the respondents-is that the sensor-provided data are available in Kanarek (Canary), a free mobile application that aggregates information from the entire network, which can be placed as a widget on the smartphone. Several of them also stated that it would be a good idea to streamline the entire project by linking air pollution data with atmospheric data and sensors with weather stations. Another idea-and a common practice among the respondents-is to combine sensors with home air purifiers.

Another issue related to the use of sensors is the previously indicated tendency to monitor air quality at home, with users' attention directed to their immediate surroundings rather than establishing relationships across the community. The local environment is the main point of reference when using sensors, but it is defined very narrowly. One's home and immediate vicinity are generally the main spaces where air quality is an important issue worth monitoring. One respondent also mentioned the school environment as an important place where children spend a lot of time:

'Children don't really care about it, but the information about the air in the vicinity of

the school would be valuable for parents' (I_18). 
The respondents portrayed no interest in the data generated by other users (unless it was necessary to compare where the air quality was worse), as expressed in the following quote:

'I checked my private site occasionally because I didn't use it [the community] to access data aggregation systems in order to find my location. I preferred to observe my sensor' (I_05).

As a result, the respondents had nearly no contact or relationships with each other within the network, hardly ever sharing data from the sensors on social media. One of the study's participants said: 'There was a period when I would take pictures of the map and put them on Facebook, but then I got over it' (I_20). Nor did they engage in contact with other Sensor.Community's users.

A similar observation can be made about users' involvement in civic initiatives that extend beyond their private and narrowly defined interests. The vast majority of the respondents did not engage in such activities or were involved to a very limited extent. This applied to both civic activities and movements for air quality protection (e.g., involvement in the work of environmental activists) and interactions with local authorities (e.g., attending informational meetings about air quality and fighting smog). Most respondents were never involved in either of the action types. They attributed their lack of commitment to individual factors (lack of time, lack of willingness to become involved), technological and regulatory problems (local authorities cannot issue decisions based on data obtained from low-cost, non-certified sensors), and reluctance from local governments. Another reason cited was the scale of the initiative-its wide coverage could translate into limited effects on the local level. This argument was raised by a respondent who said that a more local focus could contribute to the further development of the network:

'I think that a lot is lost due to such a dispersed use of the sensors (...). Local communities need to be approached. Otherwise, I go to a meeting somewhere in the city centre, but when I come back to my neighbourhood, I have no idea who might be interested in it here. It [the network] should be promoted locally' (I_19).

People who became involved in activities beyond their individual interests were an exception. One respondent in a medium-sized town managed to convince several residents to install sensors in their homes. Initially, he tried to engage as many people as possible in the project and encouraged greater involvement after a local network was established. He also used data in a completely different manner than other respondents-primarily to inform other residents via social media about the air quality in the town. He also organised meetings with residents and wrote petitions to local authorities. However, his initiatives did not bring in the expected results. During the interview, the respondent expressed great disappointment with the fact that other users depicted no interest:

\section{What do you think was the reason for this lack of interest?}

'I can't understand it. (...). We have a display board in Solec. Last year, I convinced the local authorities to show information about our Solec website and the Kanarek application on it. It was there for a while, then I organised workshops, but nobody showed up. Then the information about the workshops was displayed again. I also put it in our free local newspaper published by the Town Office of Solec. However, no one came to my latest workshop. I'm quite devastated by such a lack of interest' (I_02).

It is worth noting that the organisers of Sensor.Community in Poland are aware of this problem. On the one hand, they have high expectations regarding the activist and educational potential of the initiative; on the other hand, they can see that the participation is low:

'People don't believe it. They can't see the significance of it. I think it's worth having a sensor. It is worth putting it out there and have many people know the quality of air we breathe. It seems that if someone wants to fight locally, they should persuade their friends 
to install a smog sensor and organise workshops for them. But it isn't happening like this' (I_13).

Despite their lack of involvement, the respondents had a few proposals on how to further develop Sensor. Community and utilise the collected data. According to them, the data from the sensors were primarily of educational value and could serve to raise awareness about smog. Therefore, their most frequent answer to the question about the possible extension of data applicability was to have it used by education facilities (kindergartens and primary schools) i.e., institutions potentially most interested in the sensor operation as well as access to such data. Given their health-related motives, it is no surprise that the respondents found the link between the Sensor. Community data and epidemiological data most attractive. They also suggested that the network organisers come up with initiatives to involve the users (e.g., joint ventures), ensure a greater visibility of the data and its significance (e.g., annual reports presenting aggregated data from the entire network):

'If it was already there and all I had to do was to complete a table or something like that, I would do it. It would be like a research project in which I would gladly help' (I_08).

\section{Discussion}

The Sensor.Community users included in our study present, in most cases, very little commitment to the development of both the community of sensor owners and broadly defined local community: they are hardly interested in networking, using the collected data to raise political claims with local authorities, ensuring access to data to wider audiences, and persuading other people to install sensors.

Given the motives behind installing sensors and their usage, the network members can be described as pragmatic and individual-benefit-oriented consumers of this social initiative. While citizen science projects can serve as examples of the successful development of civic attitudes oriented to the broadly defined common good [34], Sensor.Community does not seem to fit into this framework and is rather an example of an initiative offering a specific product, the use of which does not generate an involvement wider than the closest group of family and friends.

The data usage mode is also indicative of users' consumption-based approach. They collect data primarily for their own use to take decisions regarding their everyday activities rather than share the information with others or initiate actions extending beyond their routine everyday needs. Given the expectations of the network organisers in Poland, such an approach to the use of sensors contradicts the network intentions. One of them declared: 'I don't sell sensors as a product, but I invite people to my workshops. (...). This is not a product. It is a certain experience as well as an opportunity to build awareness and knowledge on this topic' (I_01).

It is worth emphasising that the lack of participation constitutes an organisational challenge in many projects based on citizen inclusion. According to the report 'Assessing air quality through citizen science' by the European Environment Agency (EEA), 'people usually use low-cost sensor systems as individual instruments, rather than as part of a connected network' [8] (p. 47).

Nevertheless, Sensor.Community seems to carry the potential for a deeper commitment. Its users organised themselves entirely as a bottom-up initiative (without the involvement of a scientific or local government institution), using their private funds to purchase the necessary devices (they could not simply rely on their home equipment, e.g., the computer, and had to invest in sensor kits). Moreover, they expressed their willingness and shared ideas on how to ensure the initiative is more inclusive. Most proposals referred to the involvement on the organisers' part. Suggestions such as annual reporting based on the data from the entire network or combining pollution data with epidemiological data illustrate that users feel the need to make their work more meaningful. Network-wide initiatives implemented by organisers could show users that the data collected by them can be used on levels other than the individual one. This could put their work in a wider 
context, creating added value and highlighting the educational and scientific aspects of the aggregated data.

\subsection{Values and Motivation}

Why is the involvement of the examined Sensor.Community users so low? The answer to this question seems to reside primarily in the values and motivation behind the collection of air quality data. Both the reasons and data application scope were in most cases determined by two motives, health and family, with the overarching need for a sense of safety. The health- and family-related motives have already been explored as important factors of involvement in air quality monitoring [35]. While these values can shape a variety of practices, in the case of our respondents, they seem to contribute to the development of individualistic attitudes. It is worth noting that from the critical perspective, caring for one's health may be an expression of the neoliberal biopolitics of self-making oriented towards individual well-being whereby the responsibility for one's condition is shifted to the individual $[36,37]$. Air quality monitoring combined with the need to ensure health security for the self and loved ones internalises and privatises the problem of smog, placing it within the category defined by the boundaries of human body, home space, and immediate environment (neighbourhood). From this perspective, the sensor serves to fulfil the individual need arising from the willingness to take care of one's and their family's health on one's own, rather than engage in actions for a wider community.

The individual motives discussed in this article can be juxtaposed with examples of other citizen science projects related to environmental monitoring. Many of them are inspired by problems defined at the level of local community and require the collection of non-expert data to legitimise political claims. They include projects of communitybased environmental monitoring in which 'emphasis is placed on monitoring designed to promote sustainability, leadership of monitoring by the community rather than individual organisations and use of monitoring data to inform decision-making' [38] (p. 410). Such activities are typically initiated in response to negative local impact on the quality of life (e.g., pollution generated by production plants). An example may be the initiative in the Diamond community in Norco, Louisiana, whose residents used plastic buckets devised to collect and test air samples to draw the attention of local authorities to the negative health impact of the Shell chemical plant on local residents [39].

The format of Sensor.Community is different. The main difference lies in the level of the problem articulation, which determines further involvement. In the studied initiative, the problem of poor air quality is not defined at the level of local community that fights a negative phenomenon. It is defined either at a general level as a problem faced by Poland's inhabitants or at the individual level mediated by the previously discussed health- and family-related motives. The former seems too general and lacks local embeddedness to provoke civic actions. The latter is isolated to limited relationships determined by one's own body and individual home space, with the problem affecting individuals rather than groups of people.

It is also worth emphasising that personal perspective, arising from individual experience which is subjectively oriented, does not necessarily exclude civic involvement and activity. This applies to the interpretation of pollution data through the prism of common knowledge (e.g., links between the direction of the wind and prevalence of health problems attributable to smog) [20] as well as using data to define individual damage [19]. Pollution data allow people to locate the negative impact in the world they experience. Hence, the data contributes, on the one hand, to the objectivisation of the problem (through graphs and data visualisations) and, on the other, to its subjectivisation by providing the scaffolding for sensory experiences and new relationships between the individual and environment [40]. In terms of our study, it is important to notice that Sensor.Community's users represented different trajectories of action; however, their motives have proven to be largely subjective. Their subjective belief in the impact on family and health has not 
stimulated civic involvement. Moreover, their beliefs and motivation have not been used in an informed manner by the network organisers to encourage a greater user engagement.

\subsection{Organisation and Technological Solutionism}

The low civic involvement in Sensor.Community may also have arisen from how it is organised. As already mentioned, new members can join it through workshops (held by the foundation that oversees the Polish network) or out of their own initiative. The workshops are mainly practical and focus on technical aspects. The organisers' role ends once the sensor is connected to the network. The management of Sensor.Community as a project, therefore, relies on users' individual initiative and is not intended to stimulate action on a regular basis.

Other environmental citizen science initiatives can be organised and managed in an entirely different way, providing for greater user involvement. According to Mahajan et al. [41], projects of this type should consist of three key components: (1) inclusion-including as many individuals or groups as possible; (2) collaboration-ensuring opportunities for interaction between various actors (users, policy makers, experts); (3) reciprocationdevelopment and dissemination of project results. The same authors also proposed three solutions to implement said components: (1) an interactive quiz to help participants gain basic knowledge about air pollution; (2) offline questionnaire where participants can share their opinions on the project; (3) three-stage workshops during which participants not only learn to use the air quality monitoring tool but also express their opinions on it and contribute to its improvement. Further, citizen science projects routinely use activity diaries [18]—where participants regularly report the results of their actions-and data stories [42]—where data are combined with photos and user narratives for a better context and more meaning. Thus, users can witness the significance of their actions, which strengthens their pursuit of a common goal.

An interesting example is the Citi-Sense-MOB project implemented in Oslo, Norway to collect pollution data using sensors attached to bicycles and buses [31]. An important component of the project was Citizens' Observatories, where participants could process the results of their activities on a current basis. Rather than on technical issues, the work with citizens focused on their participation in the development of the principal elements of the project. During the workshop, decisions were made regarding whom to include in the project, what problems to tackle, and what kind of data to collect. Organisers encouraged participation and created space for the exchange of experiences throughout the project. This example highlights not only the objective of the actions taken but also the subjectivity of the participants. Their role is not limited to the collection of data as they are also engaged in the development of the project concept.

None of the techniques to increase user involvement have been applied on Sensor.Community in Poland. During workshops, organisers focus primarily on technological aspects rather than develop civic practices for data use with participants or teach them possible data applications. Sensor.Community does not specify a target group that would be interested in collecting data for anything other than purely individualistic reasons. Nor does it provide space for in-depth user-organiser interactions that could potentially increase user involvement. It does not cooperate with other stakeholders (public institutions, experts, local governments) in the implementation of the project. Such a collaboration may lead to greater user involvement opportunities through new relationships and extend the scope of possible interventions and practices (e.g., presenting data to stakeholders), while pointing to aspects other than individually oriented forms of data application. The latter is confirmed by studies of citizen science initiatives which reveal that even if someone joins such a project for individualistic reasons, their inclusion in the community of users may encourage them to a more meaningful participation [25].

The approach of the Sensor.Community network organisers can be described as solutionist. Technological solutionism is the belief that technological innovations themselves can be a tool to solve a problem, rather than, for example, social solutions (e.g., increased 
social capital, deeper cooperation, etc.) [43-45]. The focus on the technical aspects of air quality monitoring for network expansion can be treated as an example of technological solutionism as other aspects (cooperation with other stakeholders, exchange of experience, data sharing) are practically absent. Without them and without pre-defined user paths, the project participants employ sensors to satisfy their personal motives before they join the data collection initiative.

The lack of soft aspects, focused on inspiring more social involvement in Sensor.Community, may be due to the organisers' belief that the provision of the tool would suffice to initiate further actions against smog. Below is a quote from an interview that can be indicative of such an interpretation and the organisers' thinking in terms of technological solutionism:

'We make the tool. (...). We invest ourselves more in this tool. It's up and running, and it's already generating data. People already have access to information. It kind of works as if on its own, things are happening in the background. It's cool that providing people with sensors gives them knowledge and inspires conversations' (I_13).

Science and technology studies draw attention to the fact that public participation is developed through negotiations, relationships, and sometimes controversy [46]. Citizen science initiatives, as examples of projects involving citizens in work for the community, cannot rely on one-off interventions if they are to be effective. They must focus on the implementation of long-term processes to change the existing relationships, operating systems, and entities involved. To this end, it is necessary to think about such projects and initiatives primarily in social terms rather than strictly technological ones.

\subsection{Institutional and Technical Limitations: Lack of the Sense of Agency}

The respondents pointed to a key limitation in terms of the sensor usability-the reliability of measurements. Methodologically, low-cost sensors applied in Sensor.Community cannot match up to the expensive and certified devices employed by public entities for the purpose of nationwide air quality monitoring. The readings from the latter are much more precise than those obtained from low-cost sensors. Nevertheless, the civic sensor network is also of great value. It is accurate in showing general trends (e.g., sudden deterioration of the situation) and filling in the gaps (white spots) i.e., places not covered by the state system.

The question of data reliability is not only of a technical nature, it is also related to the perceived credibility of citizen-based initiatives. Neither public institutions responsible for the environment nor local governments recognise civic sensors' data as reliable sources of knowledge in Poland [47]. As a result, Polish law regulations, which define where and how data should be collected and interpreted, tend to be used as a pretext to delegitimise civic monitoring. Given that citizen-based networks do not meet these standards, they are not taken seriously by institutions and authorities. Simultaneously, citizen science researchers highlight that a certain level of acceptance and institutionalisation of civic science is necessary. Bottom-up actions may prove insufficient to ensure project effectiveness and achieve objectives expected by both parties; certain undertakings must also be accepted as an official stream of data [48]. This is a challenge for many citizen science projects, and it frequently determines the need to combine the potential of volunteers with that (tools and mechanisms) of institutional learning. As a result, it is possible to control and manage data along with ensuring the continuity of research on a specific issue $[27,49,50]$.

In view of the above, it is suggested that the reasons for poor user involvement in Sensor.Community should be sought in people's awareness of the methodological limitations of the sensors and resulting lack of the sense of agency. Given that public stakeholders are reluctant to recognise the value of the collected data as potential beneficiaries, its use is generally limited to private purposes. To ensure a different approach to data usage and extend the range of possible user actions, it would be necessary to reform the attitude of public institutions and local authorities which would have to admit that these data have a value. As Philips et al. [51] exhibit, one of the key factors behind a greater involvement in citizen science projects was the belief in the importance of actions implemented as part of them. 
It is also worth noting that we now have recommendations for the appropriate selection [52], calibration [53] and use [54,55] of low-cost sensors for air quality issues. Incorporating current scientific work on this problem in building citizen engagement for air quality monitoring could also influence perceptions of the reliability of data collected by citizens. Consequently, this could also contribute to changing the attitude of public air monitoring institutions and strengthen the reliability of citizen effort. It would also broaden the context of debate in the scientific community (academia, local monitoring institutions, etc.).

Concurrently, users' critical approach to data reliability proves the ignorance of some respondents concerning the value of information they collect. As one respondent stated, the value of the network increases with the number of sensors-the denser the network, the more reliable and valuable data it can produce. A dense network of sensors in a specific district or town may, to a certain extent, be an alternative to the state air quality monitoring, especially when the construction of an expensive professional station is impossible. However, this is not common knowledge among the network users included in this study.

Data management through cooperation with schools and for educational purposes is another issue frequently raised by the respondents. On the one hand, it seems to be an obvious idea to increase awareness about poor air quality. On the other, it proves that the scope of data-based practices is essentially limited to a simple transfer of knowledge and does not include, for instance, activists making claims with institutions or authorities. Most respondents cannot see the possibility of using the data collected by them to exert pressure on local governments and environment monitoring institutions, not to mention a dynamic shift in social attitudes. This conclusion seems to be confirmed by a quote from one of the interviews: 'I believe this increases awareness; however, I don't think it will convince anyone. It simply provides more information for people who are looking for it' (I_05).

\section{Summary}

This article presents the results of the qualitative research conducted on Polish users of the Sensor.Community network. Different types of motivation behind the decision to engage in the collection of air quality data are discussed. Users' motives have been found to result predominantly from the concern for the health and safety of their loved ones, as well as the need to control air quality (and ultimately the quality of life) in their immediate environment (home and neighbourhood). Their attitude can also be described as pragmatic - respondents use sensors to either take up or withdraw from daily activities (e.g., walking, outdoor sports). Even so, they do not display civic behaviour such as working for the local community. Nor do they engage in relationships with other Sensor.Community users. Based on these findings, they are described as consumers who approach sensors as tools necessary to meet their individual needs.

Three factors have been proposed to explain this status quo. First, the motives related to health and safety, as opposed to motives behind seeking a resolution to an environmental problem at the local level, may contribute to the solidification of individualistic attitudes. Individualistically oriented motivation appears to also affect the very perception of the issue of smog. Air pollution is approached as an individual challenge rather than a problem in which every individual can contribute significantly to find a solution by being involved in organised civic initiatives. Active participation could translate into a more effective use of users' potential through cooperation with public institutions and entities at all levels. Second, Sensor.Community is organised in a way that does not promote a greater involvement from the network organisers in the development of the initiative and retention of users. Instead, the network focuses predominantly on the technical aspects of operation. Third, users have no sense of agency as, in our opinion, they remain largely unaware of the value of the data they collect. Given these factors and the individualist attitudes represented by the respondents, without the rules of cooperation and collective data use, the actions of the citizens involved in Sensor.Community carry a low potential for both the 
development of the initiative in terms of citizen science and solving the problem of smog itself, even if only at the local level.

Our study reveals the problems faced by citizen science projects related to air quality. Without appropriate management and the use of specific tools dedicated to this purpose, such initiatives can become extremely utilitarian and overtly focused on participants' individual interests. Additionally, our analysis highlights the need to direct the focus on projects of this type in social terms rather than purely technological. Such initiatives require definite actions to be taken on a regular basis to maintain an appropriate level of user involvement and include people in new areas of activity. Without appropriate measures, the process of generating knowledge by non-experts will not translate into community-oriented attitudes or increased citizen involvement, and it ultimately has little chance of contributing to the resolution of the community's problem.

The presented study provides further arguments with regard to citizen science projects and their development. Given the experience from our research and conclusions from the implementation of other civic science initiatives, it can be confirmed that citizen science can not only contribute to the dissemination of technological instruments among nonprofessionals but above all to the expansion of the area of civic participation. However, the latter cannot occur within the perspective of technological solutionism. Gaining insight into the methodologies/approaches of action research and social learning in the case of environmental problems could further support the knowledge generated as part of citizen science.

Author Contributions: Conceptualization. M.W.; methodology, M.W. and J.S.; validation, J.S. and K.T.; formal analysis, M.W., J.S. and K.T.; investigation, M.W., J.S. and K.T.; writing—original draft preparation, M.W.; writing—review and editing, J.S. and K.T.; supervision M.W. All authors have read and agreed to published version of the manuscript.

Funding: This research was funded by Polish National Science Centre, grant number UMO-2017/25/Z /HS6/03046.

Institutional Review Board Statement: Not applicable.

Informed Consent Statement: Not applicable.

Data Availability Statement: The data supporting the reported results in the present study will be available on request from the corresponding author.

Conflicts of Interest: The authors declare no conflict of interest.

\section{References}

1. European Environmental Agency. Air Quality in Europe-2019 Report; Publications Office of the European Union: Luxembourg, 2019.

2. CBOS (Centrum Badania Opinii Społecznej-Public Opinion Research Center). Polacy o Smogu; Warszawa, Poland, 2019. Available online: https:/ / cbos.pl/SPISKOM.POL/2019/K_033_19.PDF (accessed on 9 August 2021).

3. Brimblecombe, P.; Makra, L. Selections from the History of Environmental Pollution, with Special Attention to Air Pollution. Part 2: From Medieval Times to the 19th Century. Int. J. Environ. Pollut. 2004, 22, 641-656. [CrossRef]

4. World Health Organization. Health Risks of Particulate Matter from Long-Range Transboundary Air Pollution; WHO Regional Office for Europe: Copenhagen, Denmark, 2006.

5. Frankowski, J. Attention: Smog Alert! Citizen Engagement for Clean Air and Its Consequences for Fuel Poverty in Poland. Energy Build. 2020, 207, 109525. [CrossRef]

6. Tomaszyk, M. Action Against Smog at Local Government Level in Relation to Urban Public Transport: Evidence from Selected Polish Cities. Urban Dev. Issues 2017, 55, 57-66. [CrossRef]

7. Hachem, S.; Georgios, M.; Animesh, P.; Valérie, I.; Rajiv, B. Sense2Health: A Quantified Self Application for Monitoring Exposure to Environmental Pollution. In Proceedings of the SENSORNET, Angers, France, 11-13 February 2015. Available online: https:/ / hal.inria.fr/hal-01102275/document (accessed on 9 August 2021).

8. European Environment Agency (EEA). Assessing Air Quality through Citizen Science; EEA Report No 19/2019. Copenhagen, Denmark, 2019. Available online: https://www.eea.europa.eu/publications/assessing-air-quality-through-citizen-science (accessed on 9 August 2021). 
9. Allen, L.B. Uneasy Alchemy: Citizen and Experts in Louisiana's Chemical Corridor Disputes; The MIT Press: Cambridge, MA, USA, 2003.

10. Corburn, J. Street Science: Community Knowledge and Environmental Health Justice; The MIT Press: Cambridge, MA, USA, 2005.

11. Kinchy, A. Citizen Science and Democracy: Participatory Water Monitoring in the Marcellus Shale Fracking Boom. Sci. Cult. 2016, 26, 88-110. [CrossRef]

12. Ottinger, G.; Sarantschin, E. Exposing Infrastructure: How Activists and Experts Connect Ambient Air Monitoring and Environmental Health. Environ. Sociol. 2017, 3, 155-165. [CrossRef]

13. Broeder, L.D.; Devilee, J.; Van, O.H.; Schuit, J.; Wagemakers, A. Citizen Science for Public Health. Health Promot. Int. 2018, 33, 505-514. [CrossRef] [PubMed]

14. Wynne, B. May the Sheep Safely Graze? A Reflexive View of the Expert-Lay Knowledge Divide. In Risk, Environment and Modernity: Toward a New Ecology; Lash, S., Szerszynski, B., Wynne, B., Eds.; Sage: London, UK, 1998; pp. 44-83.

15. Callon, M.; Lascoumes, P.; Barthe, Y. Acting in Uncertain World; The MIT Press: Cambridge, MA, USA, 2009.

16. Frickel, S.; Gibbon, S.; Howard, J.; Kempner, J.; Ottinger, G.; Hess, D.J. Undone Science: Charting Social Movement and Civil Society Challenges to Research Agenda Setting. Sci. Technol. Hum. Values 2010, 35, 444-473. [CrossRef] [PubMed]

17. Connors, J.P.; Lei, S.; Kelly, M. Citizen Science in the Age of Neogeography: Utilizing Volunteered Geographic Information for Environmental Monitoring. Ann. Assoc. Am. Geogr. 2010, 102, 1267-1289. [CrossRef]

18. Constant, N. Role of Citizen Science in Air Quality Monitoring. In Urban Pollution. Science and Management; Charlesworth, S.M., Booth, C.A., Eds.; Wiley and Sons: Oxford, MS, USA, 2019; pp. 303-312.

19. Gabrys, J. Citizen Sensing, Air Pollution and Fracking: From 'Caring About Air' to Speculative Practices of Evidence Harm. Sociol. Rev. 2017, 65, 172-192. [CrossRef]

20. Bush, J.; Moffatt, S.; Dunn, C. Even the Birds Round Here Cough': Stigma, Air Pollution and Health in Teesside. Health Place 2001, 7, 47-56. [CrossRef]

21. Ottinger, G. Opening black boxes. Environmental justice and injustice through the lens of science and technology studies. In The Routledge Handbook of Environmental Justice; Holifield, R., Chakraborty, J., Walker, G., Eds.; Routledge: London, UK; New York, NY, USA, 2017; pp. 89-100.

22. Ottinger, G. Making Sense of Citizen Science: Stories as a Hermeneutic Resource. Energy Res. Soc. Sci. 2017, 31, 41-49. [CrossRef]

23. Huyse, H.; Bachus, K.; Merlevede, T.; Delanoeije, J.; Knipprath, H. Societal Impact of the Citizen Science Project “CurieuzeNeuzen Vlaanderen"; HIVA—Research Institute for Work and Society: Leuven, Belgium, 2019.

24. Mahajan, S.; Luo, C.-H.; Wu, D.-Y.; Chen, L.-J. From Do-It-Yourself (DIY) to Do-It-Together (DIT): Reflections on Designing a Citizen-Driven Air Quality Monitoring Framework in Taiwan. Sustain. Cities Soc. 2021, 66, 102628. [CrossRef]

25. Maisonneuve, N.; Stevens, M.; Ochab, B. Participatory Noise Pollution Monitoring Using Mobile Phones. Inf. Polity 2010, 15, 51-71. [CrossRef]

26. Tommey, A.H.; Strehlau-Howay, L.; Manzonillo, B.; Thomas, C. The Place-Making Potential of Citizen Science: Creating Social-Ecological Connections in an Urbanized World. Landsc. Urban Plan. 2020, 200, 103824. [CrossRef]

27. Jalbert, K.; Kinchy, A. Sense and Influence: Environmental Monitoring Tools and the Power of Citizen Science. J. Environ. Policy Plan 2016, 18, 379-397. [CrossRef]

28. Lewenstein, B. Can We Understand Citizen Science? J. Sci. Commun. 2016, 15, 1-5. [CrossRef]

29. Owen, R.P.; Parker, A.J. Citizen Science in Environmental Protection Agencies. In Citizen Science: Innovation in Open Science, Society and Policy; Hecker, S., Haklay, M., Bowser, A., Makuch, Z., Vogel, J., Bonn, A., Eds.; UCL Press: London, UK, 2018; pp. 284-300. [CrossRef]

30. Fähnrich, B. Digging Deeper? Muddling Through? How Environmental Activists Make Sense and Use of Science-An Exploratory Study. J. Sci. Commun. 2018, 17, 1-18. [CrossRef]

31. Castell, N.; Kobernus, M.; Liu, H.-L.; Schneider, P.; Lahoz, W.; Berre, A.J.; Noll, J. Mobile Technologies and Services for Environmental Monitoring: The Citi-Sense-MOB approach. Urban Clim. 2015, 14, 370-382. [CrossRef]

32. Sauermann, H.; Vohland, K.; Antoniou, V.; Balázs, B.; Göbel, C.; Karatzas, K.; Mooney, P.; Perelló, J.; Ponti, M.; Samson, R.; et al. Citizen Science and Sustainability Transitions. Res. Policy 2020, 49, 103978. [CrossRef]

33. Füchsling, T.; Schäfer, M.S.; Metag, J. Who Wants to be a Citizen Scientist? Identifying the Potential of Citizen Science and Target Segments in Switzerland. Public Underst. Sci. 2019, 28, 652-668. [CrossRef] [PubMed]

34. Conrad, C.C.; Hilchey, K.G. A Review of Citizen Science and Community-Based Environmental Monitoring: Issues and Opportunities. Environ. Monit. Assess. 2011, 176, 273-291. [CrossRef]

35. I'Her, G.; Servières, M.; Siret, D. Citizen as Sensors' Commitment in Urban Public Action: Case Study on Urban Air Pollution. Int. J. E-Plan. Res. 2019, 8, 42-59. [CrossRef]

36. Lupton, D. The Imperative of Health: Public Health and the Regulated Body; Sage: London, UK, 1995.

37. Ayo, N. Understanding Health Promotion in a Neoliberal Climate and the Making of Health Conscious Citizens. Crit. Public Health 2012, 22, 99-105. [CrossRef]

38. Whitelaw, G.; Vaughan, H.; Craig, B.; Atkinson, D. Establishing the Canadian Community Monitoring Network. Environ. Monit. Assess. 2003, 88, 409-418. [CrossRef] [PubMed]

39. Ottinger, G. Buckets of Resistance: Standards and the Effectiveness of Citizen Science. Sci. Technol. Hum. Values 2010, 35, 244-270. [CrossRef] 
40. Calvillo, N. Political Airs: From Monitoring to Attuned Sensing Air Pollution. Soc. Stud. Sci. 2018, 48, 372-388. [CrossRef]

41. Mahajan, S.; Kumar, P.; Pinto, J.A.; Riccetti, A.; Schaaf, K.; Comprodon, G.; Smári, V.; Passani, A.; Forino, G. A Citizen Science Approach for Enhancing Public Understanding of Air Pollution. Sustain. Cities Soc. 2020, 52, 101800. [CrossRef]

42. Gabrys, J.; Pritchard, H.; Barratt, B. Just Good Enough Data: Figuring Data Citizenships Through Air Pollution Sensing and Data Stories. Big Data Soc. 2016, 3, 1-14. [CrossRef]

43. Morozov, E. To Save Everything, Click Here: The Folly of Technological Solutionism; Public Affairs: New York, NY, USA, 2013.

44. Rosner, L. The Technological Fix: How People Use Technology to Create and Solve Problems; Routledge: London, UK; New York, NY, USA, 2004.

45. Afeltowicz, Ł.; Pietrowicz, K. Solutionist interventions and their unforeseen consequences: A preliminary catalogue of often commited errors. In Proceedings of the National Interdisciplinary Scientific Conference TechSpo: Power of Algorithms, Krakow, Poland, 1-4 September 2018. [CrossRef]

46. Chilvers, J.; Kearnes, M. (Eds.) Remaking Participation. Science, Environment and Emergent Publics; Routledge: London, UK; New York, NY, USA, 2016.

47. Wróblewski, M.; Goszczyński, W. Konflikty wokół monitoringu jakości powietrza w Polsce. Infrastruktury, standardy i dane. Stud. Socjol. 2020, 4, 155-182.

48. Henderson, S. Citizen Science Comes of Age. Front. Ecol. Environ. 2012, 10, 283. [CrossRef]

49. Savan, B.; Morgan, A.J.; Gore, C. Volunteer Environmental Monitoring and the Role of the Universities: The Case of Citizens' Environment Watch. Environ. Manag. 2003, 31, 561-568. [CrossRef]

50. Irwin, A. No PhDs Needed: How Citizen Science is Transforming Research. Nature 2018, 562, 480-482. [CrossRef]

51. Phillips, T.B.; Ballard, H.T.; Lewenstein, B.V.; Bonney, R. Engagement in Science Through Citizen Science: Moving Beyond Data Collection. Sci. Educ. 2019, 103, 665-690. [CrossRef]

52. Karagulian, F.; Barbiere, M.; Kotsev, A.; Spinelle, L.; Gerboles, M.; Lagler, F.; Redon, N.; Crunaire, S.; Borowiak, A. Review of the Performance of Low-Cost Sensors for Air Quality Monitoring. Atmosphere 2019, 10, 506. [CrossRef]

53. Lin, Y.; Dong, W.; Chen, Y. Calibrating Low-Cost Sensors by a Two-Phase Learning Approach for Urban Air Quality Measurement. Proc. ACM Interact. Mob. Wearable Ubiquitous Technol. 2018, 2, 1-18. [CrossRef]

54. Brattich, E.; Bracci, A.; Zappi, A.; Morozzi, P.; Di Sabatino, S.; Porcù, F.; di Nicola, F.; Tositti, L. How to Get the Best from Low-Cost Particulate Matter Sensors: Guidelines and Practical Recommendations. Sensors 2020, 20, 3073. [CrossRef] [PubMed]

55. Liu, X.; Jayaratne, R.; Thai, P.; Kuhn, T.; Zing, I.; Christensen, B.; Lamont, R.; Dunbabin, M.; Zhu, R.; Gao, J. Low-cost sensors as an alternative for long-term air quality monitoring. Environ. Res. 2020, 185, 109438. [CrossRef] [PubMed] 